of our sister genera.

So a skirmish it may be, but it is a challenging and stimulating one that deserves to be widely assimilated and discussed. It may well prove to be an influential landmark in what is starting to look like a pendulum swing, from an era of social evolutionary modelling obsessed with selfishness and Machiavellian manoeuvring, to one that seeks to incorporate evidence of real niceness and community spirit, without a return to naive group-selection theory. $\square$

Andrew Whiten, currently at Emory University, Atlanta, Georgia, USA, is in the School of Psychology, University of St Andrews, St Andrews, Fife KY16 9JU, UK.

\section{Why we age}

Roger Short

Cheating Time: Science, Sex and Ageing. By Roger Gosden. Macmillan: 1996. Pp. 339. £16.99.

THE blue-rinse set must hope against hope that age will not weary them, nor the years condemn them to Shakespeare's Seventh Age of second childishness and mere oblivion, sans teeth, sans eyes, sans taste, sans everything. Fear of ageing has haunted us forever. A popular scientific account of the biological basis for ageing should therefore be welcomed by an evergrowing proportion of the population.

There can be little doubt that lifespan is both one of nature's design constraints and subject to selection. Mike Rose's intriguing experiment with the fruitfly Drosophila shows how easily and rapidly increased longevity can be selected for, so we must ask ourselves what are the selection pressures that have led to such enormous differences in lifespan between species? Why have the tortoise and the hare chosen to run such very different races? Unfortunately, Roger Gosden does not really explore this problem in any depth, even though he opens with an account of Antechinus stuartii, Australia's spectacular marsupial shrew, where all males die at the end of each mating season, broken down by sex rather than age, because celibacy or castration will grant them an extra year of life. Ecologically it is not difficult to see method in their mating madness, but why should the rockfish and the raven, the tortoise and the elephant, the parrot and people live such long lives? There is much that we do not understand.

The human menopause, one of the central themes of this book, also deserves more discussion. Gosden rather lamely concludes that "it is more likely to have crept on to the stage by default". He finds it difficult to see any positive advantage in it, regarding it as "more a handicap than a benefit". Perhaps he would profit from reading Germaine Greer's alternative viewpoint in The Change. Because humans have the longest period of childhood dependency of any animal, it surely makes good sense that the mother should stop producing children well before she is likely to die, so that her lastborn is not seriously disadvantaged by her death. And in many traditional societies, grandmothers are not expected to bear children because they must assume a new role of caring for their grandchildren. For many women, a new life begins at 50 . The shortened human female reproductive lifespan also has important consequences for our mating system. When older men remarry, they almost invariably choose a younger, pre-menopausal wife. The net result is that there are more men who father children by more than one wife than there are wives who have children by more than one husband. In other words, communities that practise serial monogamy are effectively polygynous. This may explain the persistence of such marked sexual dimorphisms in height and body build.

Perhaps the most interesting part of the book, and certainly the most readable, is the historical account of the development of 'rejuvenation therapies', starting in the late nineteenth century with the vain attempt of the 72-yearold Professor Charles-Édouard BrownSéquard in Paris to restore his lost youth by injecting himself with aqueous extracts of guinea-pig and dog testicles. With a whimsical twist, Gosden even dedicates his book to Brown-Séquard, who at least was objective enough to realize that his therapeutic discovery might be an illusion (it was), so he offered to supply his extracts, at his own expense, to any physician who cared to investigate his claims; within a year, 1,200 had taken up his offer and were trying it on their patients. The results were unconvincing, and the method soon fell into disrepute, but it was probably Brown-Séquard's spectacular claims that drew people's attention to the potentially powerful effects of the body's glandular secretions, later called hormones, leading to the development of that eminently respectable scientific discipline, endocrinology.

The scene then shifted from Paris to Vienna, when Professor Eugene Steinach claimed that the body's own production of testosterone was stimulated by vasectomy (it wasn't). Even the poet W. B. Yeats was Steinached at the age of 69 because of his declining productivity. Vasectomy then gave way to testicular grafting, and Serge Voronoff, a French surgeon of Russian Jewish extraction, and his American counterpart, Max Thorek, started a fashion for testicular transplants, politely known as 'monkey glands'. The large testicles of chimpanzees made

\section{IMAGE UNAVAILABLE FOR COPYRIGHT REASONS}

Serge Voronoff: exponent of the testicle.

it possible to treat several men per animal, the grafts being placed in the scrotal sac of men seeking rejuvenation. With the recent isolation of a HIV-1-type retrovirus from wild chimpanzees, one wonders how close those thoughtless surgeons came to initiating an HIV pandemic immediately after the end of the First World War. It would be interesting to know what Voronoff's and Thorek's many patients eventually died of - perhaps their elderly and debilitated state was a blessing in disguise.

Today we tend to see testosterone more as a poison, responsible for aggression and excessive muscular development, although curiously Gosden regards such claims as unproven. Certainly, castrated men, like Antechinus, seem to live significantly longer, but the therapy has never caught on.

One of the most intriguing speculations about human ageing was in Aldous Huxley's Brave New World, which Gosden does not mention. Huxley advocated the use of "soma", a drug designed for the elderly which would be extremely pleasant to take, even addictive, but which would greatly shorten life expectancy rather like tobacco. As countries move inexorably towards population stabilization, the age pyramid will become more columnar in shape, with ever-increasing numbers of elderly pensioners, living off the economy rather than contributing to it. Those in developed countries will be able to afford expensive palliative care, such as cancer chemotherapy or organ transplantation; most of their lifetime's expenditure on health will occur in the last few years of life, to buy themselves a little extra time at great cost. If life expectancy could be reduced by taking 
"soma", there would be enormous financial savings on pensions, freeing capital for re-investment in the economy. Voluntary euthanasia is another alternative, but it is unlikely to find wide acceptance other than in the terminal phases of a chronic illness, for like Julius Caesar, we would probably all wish that our deaths might be unexpected.

If gradual senescence is our destiny, then economic incentives will make gerontology the pre-eminent medical specialty in developed countries. Meanwhile, nostrums that claim to prolong and improve the quality of life will continue to plague us. Gosden's book failed to anticipate the current US craze for melatonin as an anti-ageing hormone, based on the slenderest of evidence from animal stud- ies. Sadly, pseudoscientific works such as The Melatonin Miracle by Walter Pierpaoli and William Regelson and Melatonin: The Anti-Ageing Hormone by Suzanne Levert have become bestsellers in US health food stores, and the Food and Drug Administration seems unwilling, or unable, to protect the gullible American public from gross misinformation and exploitation. Gosden's first foray into popular science writing about ageing will not compete with this pulp market, but at least his scientific integrity remains intact, for he has tried to tell the truth to a wider audience. In this, he has succeeded.

Roger Short is in the Department of Obstetrics, University of Melbourne, 132 Grattan Street, Carlton, Victoria 3053, Australia.

\section{I chat, thereby I groom}

\section{Derek Bickerton}

Grooming, Gossip and the Evolution of Language. By Robin Dunbar. Faber: 1996. Pp. 209. £15.99, \$22.95.

EVER since we discovered we were apes, there has been pressure to explain human behaviour in terms of our primate ancestry. Surely, more of what we do is apelike than many would like to think - but is all of it? Language, arguably our best trick, offers slippery terrain for anyone committed to gradualist, unpunctuated views on evolution.

Undeterred, and armed with impressive credentials, including professorships in both psychology and biological anthropology, and field research on primates, Robin Dunbar confidently attacks the knotty issue of language origins. In breezy, insouciant prose, aiming at a nonspecialist audience, he proposes that language began not as a how-to manual for hunters but as a way of cementing alliances when our ancestors' social groups reached an unwieldy size.

Recent studies show how alliances between individuals play crucial roles in primate societies, counteracting the tyranny of alpha animals. These alliances are based on mutual grooming, but grooming takes time, up to 20 per cent in some species. As hominid groups grew, Dunbar claims, more alliances were needed, so more time was spent on grooming. At some point between 20 and 40 per cent, grooming would have interfered with other vital functions. Language would then have evolved as a grooming substitute, enabling our ancestors to establish and reinforce bonds with several individuals simultaneously.

Dunbar supports this ingenious and original proposal with cross-species correlations between brain size and group size. Primates living in larger groups have bigger brains, perhaps because they need them to keep track of more complex social networks. Statistics from several

\section{IMAGE UNAVAILABLE FOR COPYRIGHT REASONS}

sources point to an optimal human group size of around 150 individuals (three times that of any other primate), making a grooming substitute indispensable. Further support is drawn from studies showing that most conversation consists of gossip about one's own or one's acquaintances' activities - a kind of verbal grooming.

But here Dunbar commits the Fallacy of Most Frequent Use. By this reasoning, computers were invented to play video games or surf the Net, while insects grew wings in order to fly ("A cooling device? Nonsense! How often do insects use wings to cool themselves nowadays?"). In evolution, faculties often appear with one function, then get co-opted for something completely different.

Other logical flaws mar Dunbar's thesis. He assumes (with no hard evidence) that group size increased in lockstep with the brain, so one can actually pinpoint the time $(500,000$ years ago) when growing numbers forced language to emerge. But a correlation holding within the narrow range of brains below $400 \mathrm{~cm}^{3}$ does not necessarily apply when that size is quadrupled. Dunbar sees that additional motivation for group-size increase is needed. Wisely, he drops two shaky possible explanations - protection from predators, protection from members of the same species - only to adopt a third: our ancestors became nomads. But he fails to show that nomadic primates have larger groups than others, and ignores the fact that our ancestors were not, until very recently, nomads. Migration does not equal nomadism, and caves in China were inhabited continuously for countless millennia.

But language itself holds the worst pitfalls. No-one would dare to write about, say, the evolution of sex without having spent years studying all aspects of sexual reproduction. Why, apparently, can such an apprenticeship be so freely dispensed with when the topic is the evolution of language?

Blithely ignoring the many arguments against continuity between language and animal communica-

tion systems, Dunbar assumes that language developed seamlessly from primate vocalizations, which, when "a more efficient mechanism for bonding was needed... began to acquire meaning". How was this amazing feat accomplished? Dunbar seems not even to realize how amazing it was. When he gets more specific, he commits four solecisms in one sentence. New Guinea's language is not "Pison", but Tok Pisin; $\mathrm{BEV}$ is not limited to "the northeastern US"; "nation language" refers to ancestral languages of Caribbean islanders, not those they speak nowadays; and Krio, as its name suggests, is a creole not a pidgin.

The book's jacket illustration by Hayden Corner nicely captures the current landscape of language evolution studies: isolated mesas of fact separated by yawning canyons of speculation. To cross the latter requires ropes of tightly woven argument, sadly lacking here. It helps to know a bit about language, too.

Derek Bickerton is in the Department of Linguistics, University of Hawaii at Manoa, Moore Hall 569, 1890 East-West Road, Honolulu, Hawaii 96822, USA. 